\title{
Spontaneous pregnancy after prepubertal haematopoietic cell transplantation
}

\author{
Eek Chaw Tan, Hemashree Rajesh*
}

Department of Obstetrics and Gynecology, Singapore General Hospital, Singapore

Received: 27 December 2017

Accepted: 24 January 2018

\section{*Correspondence:}

Dr. Hemashree Rajesh,

E-mail: hemashree.rajesh@singhealth.com.sg

Copyright: ( $)$ the author(s), publisher and licensee Medip Academy. This is an open-access article distributed under the terms of the Creative Commons Attribution Non-Commercial License, which permits unrestricted non-commercial use, distribution, and reproduction in any medium, provided the original work is properly cited.

\begin{abstract}
Spontaneous pregnancy after haematopoietic cell transplantation (HCT) is rare due to an increase incidence of premature ovarian failure resulting from pre-transplantation conditioning regimes. Increased number of long term survival of HCT patients has brought forth their fertility into focus. In this article, we reported a 34 years old woman who underwent HCT at prepubertal age and had a spontaneous pregnancy. In addition, we reviewed literature on fertility outcome in HCT survivors and the associated risk factors.
\end{abstract}

Keywords: Hematopoietic cell transplantation, Prepubertal, Spontaneous pregnancy

\section{INTRODUCTION}

HCT is curative for various haematological diseases such as leukaemia, lymphoma, thalassemia, sickle cell anaemia and aplastic anaemia. Improved transplant outcome and better supportive care have increased the long-term survival of HCT patients. This has also surfaced quality of life issues including fertility.

Prior to HCT procedure, a conditioning regimen is necessary to provide adequate immunosuppression and prevent rejection of the transplanted graft. These include chemotherapy and irradiation which cause germ cell injury and gonadal dysfunction leading to infertility. Conditioning regimes can be myeloablative or nonmyeloablative regimes. A myeloablative (MA) regimen aims to destroy all the cells in the bone marrow prior to new hemotopoietic stem cell infusion. Non myeloablative (NMA) regimens cause minimal cytopenia (but significant lymphopenia). They do not require cell support and focus on immunosuppression to allow engraftment. Single or combination agents used for myeloablation are more toxic than non-myeloablative regimes. ${ }^{1-4}$ Limited studies have been done to compare fertility outcome of both regimes. ${ }^{5}$ Rates of conception in women among the HCT survivors have ranged from 0.6$5.5 \%{ }^{6,7}$ They had a 36-fold lower conception rate compared to their siblings. ${ }^{6}$ The fertility prognosis varies with pre-transplant conditioning regimes. ${ }^{8}$

\section{CASE REPORT}

A 34 years old nulliparous woman with a history of aplastic anaemia came to our subfertility clinic after trying to conceive for 2 years. She was diagnosed to have severe aplastic anaemia at 7 years of age and had an allogeneic bone marrow transplant 4 years later.

Prior to the transplant, she was conditioned with cumulative intravenous cyclophosphamide $6.5 \mathrm{~g}$ and total lymphoid irradiation $750 \mathrm{cGy}$ in 1 fraction. Post operatively, she was given cyclosporin $\mathrm{A}$ and methotrexate for immunosuppression. She was followed up by haematology for a few years and discharged without any long-term medication. She attained spontaneous puberty 2 years later at 13 years of age. 
Thereafter she had regular menses every 21 days. She was married for 6 years and consulted us for fertility. At fertility workup, her husband's semen was unremarkable. Her FSH was $12.5 \mathrm{U} / \mathrm{L}$ with a low antral follicle count of 8. She was offered in vitro fertilisation (IVF) in view of her low ovarian reserve and underwent a hysteroscopy polypectomy for a $0.8 \mathrm{~cm}$ endometrial polyp. However, she conceived immediately in the following cycle while awaiting IVF workup. In view of the interesting presentation, we reviewed the literature over the past 20 years to identify fertility outcome after HCT.

\section{DISCUSSION}

HCT is known to reduce fertility in long-term survivors. The European Group for Blood and Marrow Transplantation (EBMT) study reported that the overall pregnancy rate after bone marrow transplant was $0.6 \%$. Data from Center for international blood and marrow transplant research (CIBMTR) showed a $5.5 \%$ conception rate among HCT survivors compared to their siblings ( $70 \%$ conception rate). Overall HCT survivors had lower prevalence of conception. ${ }^{6,7}$

Radiation-based conditioning in HCT usually refers to total body irradiation (TBI). Patients who undergo total body irradiation have a higher prevalence of infertility compared to others (odds ratio 3.32, $\mathrm{P}=0.003) .{ }^{6} \mathrm{~A}$ minority of HCT survivors recover from gonadal function and rarely get pregnant. ${ }^{9,10}$ The dosage of radiation affects the conception rate. An ovarian dosage of 15 Gy can lead to irreversible infertility even in prepubertal women. ${ }^{11}$ A TBI dose of 12 Gy can cause ovarian damage in all the patients over 10 years old and half of the patients before 10 years old. ${ }^{12}$

Total lymphoid irradiation (TLI) was first introduced in 1977 to minimise complications from TBI and facilitate graft uptake. Limited studies have been done on the effect of total lymphoid irradiation on subfertility. Charles at el compared short-term high-dose cyclophosphamide combined with single-dose total lymphoid irradiation (Group 1) versus high-dose chemotherapy plus singledose total body irradiation (Group 2). Around 50\% of the patients in Group I continued to have regular menses and normal gonadotropin levels, 36 months post-BMT, while all the patients in Group 2 had elevated plasma levels of FSH and LH over a 17 to 45 -month period of time. None of the patients in Group 2 menstruated after undergoing HCT. To our knowledge, there are no publications on the conception rate in patients who undergo chemotherapy with total lymphoid irradiation. ${ }^{8}$

Studies had showed the treatment with cyclophosphamide in a cumulative dose of 12 to $25 \mathrm{~g}$ increases the risk of amenorrhea (ranged 27-60\%). ${ }^{13-18}$ More than $80 \%$ of these patients had premature ovarian failure. Risk factors for sustained amenorrhea are patient's age when cyclophosphamide started and cumulative dosage of cyclophosphamide. Huong et al and Mok et al reported that with the use of $12 \mathrm{~g}$ and $18 \mathrm{~g}$ cumulative dose of cyclophosphamide respectively had resulted in $10 \%$ risk of amenorrhea in patients less than 30 years of age compared with $60 \%$ in patients above 40 years old. ${ }^{11,18}$ The risk of amenorrhea is low if the patient received a cumulative cyclophosphamide dose of less than $10 \mathrm{~g} .{ }^{19}$ The route of administration is not related to the risk of amenorrhea. $^{20}$

Nonmyeloablative regimes are more likely to preserve fertility compared to myeloablative regimes as the dosage of TBI and chemotherapy is lower. ${ }^{10,21,22}$ In addition, recent data have shown that similar outcomes are possible between nonmyeloablative and myeloablative regimes among HCT survivors in certain disorders such as lymphoma, chronic lymphocytic leukaemia, acute myelogenous leukaemia and myelodysplastic syndrome. ${ }^{23-25}$ Therefore, fertility outcome with nonmyeloablative regimes warrants further research and study.

The patients' age at the time of bone marrow transplant could influence the recovery of ovarian function. Patient underwent HCT at a younger age have better prognosis in preserving their fertility. Sander's et al reported that 32 out of 43 women who had cyclophosphamide alone as a preconditioning regime subsequently had normal gonadotrophin levels and menstruation but return of ovarian function was less likely over the age of 26 years. ${ }^{10}$ Alison at el reported that the pregnancy rate was markedly reduced when bone marrow transplant occurred at the later age (>20 years old). ${ }^{5}$ Matsumoto et al concluded that younger girls had a higher incidence of menarche than older girls (Mean (SD), 7.2 (0.5) versus 11.1 (1.7) years). Basal FSH began to rise to menopausal concentrations after 10 years of age, and girls who did not experience menarche had a sustained rise in FSH concentrations. Among those with a raised $\mathrm{FSH}, 5$ girls experienced menarche while serum FSH values were decreasing and 4 girls achieved menarche while FSH remained elevated. ${ }^{26}$

Several studies have reported pregnancy outcomes among female HCT survivors. Carter et al reported no significant increase in miscarriage and stillbirth rate in these patients compared to their siblings. ${ }^{6}$ However there was no comprehensive analysis to correlate each conditional regime toward the pregnancy outcome. Sanders et al reported that female HCT survivors who received TBI had a $38 \%$ miscarriage rate after 10.0 Gy single exposure or 12-14.0 Gy fractionated exposure. There were no miscarriages among patients who had TBI less than 5-8 Gy. Furthermore, patients who received cyclophosphamide had a $7 \%$ miscarriage rate. ${ }^{27}$ There is no clear data to show that HCT increased the risk of preterm labour and low birth weight infants. ${ }^{21,22,28}$ Further studies are required for appropriate conclusions to be drawn. There is no increased risk of congenital abnormality among the children of HCT survivors. $^{21,22,27,28}$ 


\section{CONCLUSION}

In conclusion, patients who received TBI have a low likelihood of pregnancy. TBI patients are more prone to an increased miscarriage rate depending on the quantum of radiation. Our patient received total lymphoid irradiation and cyclophosphamide (cumulative dose of $6.5 \mathrm{~g}$ ) as a conditioning regime and had a spontaneous pregnancy. This is probably due to the nonmyeloablative nature of her regimen. Limited studies have reported pregnancy and miscarriage rate among patients who had received this combination. Further studies are necessary to compare various conditioning regimes and elucidate the optimal one for the treatment of haematological disorders requiring HCT with a better fertility outcome.

\section{ACKNOWLEDGMENTS}

Authors express sincere thanks to the patient for giving the authors permission for the publication

Funding: No funding sources

Conflict of interest: None declared

Ethical approval: Not required

\section{REFERENCES}

1. Khouri IF, Keating M, Körbling M, Przepiorka D, Anderlini $\mathrm{P}$, O'Brien S, et al. Transplant-lite: induction of graft-versus-malignancy using fludarabine-based nonablative chemotherapy and allogeneic blood progenitor-cell transplantation as treatment for lymphoid malignancies. J Clin Oncol 1998; 16:2817.

2. Champlin R, Khouri I, Shimoni A. Harnessing graftversus-malignancy: non-myeloablative preparative regimens for allogeneic haematopoietic transplantation, an evolving strategy for adoptive immunotherapy. Br J Haematol. 2000;111:18.

3. Giralt S, Ballen K, Rizzo D. Reduced-intensity conditioning regimen workshop: defining the dose spectrum. Report of a workshop convened by the center for international blood and marrow transplant research. Biol Blood Marrow Transplant 2009; $15: 367$.

4. Bacigalupo A, Ballen K, Rizzo D. Defining the intensity of conditioning regimens: working definitions. Biol Blood Marrow Transplant 2009; $15: 1628$.

5. Loren AW, Chow E, David A. Jacobsohn. Pregnancy after hematopoietic cell transplantation: a report from the late effects working committee of the center for international blood and marrow transplant research (CIBMTR). Biol Bone Marrow Transplant. 2011;1:157-66.

6. Carter A, Robison LL, Francisco L. Prevalence of conception and pregnancy outcomes after hematopoietic cell transplantation: report from the bone marrow transplant survivor study. Bone Marrow Transplant. 2006;37:1023-9.
7. Salooja N, Szydlo RM, Socie G. Pregnancy outcomes after peripheral blood or bone marrow transplantation: a retrospective survey. Lancet. 2001;358:271-6.

8. Sklar CA, Kim TH, Williamson JF, Ramsay NKC. Ovarian function after successful bone marrow transplantation in postmenarcheal females. Med Pediatr Oncol. 1983; 1:361-4.

9. Sanders JE, Hawley J, Levy W, Gooley T, Buckerner $\mathrm{CD}$, Deeg HJ, et al. Pregnancies following high-dose cyclophosphamide with or without high-dose busulfan or total-body irradiation and bone marrow transplantation. Blood. 1996;87:3045-52.

10. Sanders JE, Buckner CD, Leonard JM. Late effects on gonadal function of cyclophosphamides, totalbody irradiation, and marrow transplantation. Transplant. 1983;36:252-5.

11. Mertens AC, Ramsay NK, Kouris S, Neglia JP. Patterns of gonadal dysfunction following bone marrow transplantation. Bone Marrow Transplant. 1998;22:345-50.

12. Meirow D, Nugent D. The effects of radiotherapy and chemotherapy on female reproduction. Hum Reprod Update. 2001;7:535-43.

13. Austin III HA, Klippel JH, Balow JE. Therapy of lupus nephritis. Controlled trial of prednisone and cytotoxic drugs. N Engl J Med. 1986;314:614-9.

14. Boumpas DT, Austin III HA, Vaughan EM. Controlled trial of pulsemethylprednisolone versus two regimens of pulse cyclophosphamide in severe lupus nephritis. Lancet. 1992;340:741-5.

15. Illei GG, Takada K, Parkin D. Renal flares are common in patients with severe proliferative lupus nephritis treated with pulse immunosuppressive therapy. Long-term follow-up of a cohort of 145 patients participating in randomized controlled studies. Arthritis Rheum. 2002;46:995-1002.

16. Illei GG, Austin III HA, Crane M. Combination therapy with pulse cyclophosphamide plus pulse methylprednisolone improves long-term renal outcome without adding toxicity in patients with lupus nephritis. Ann Intern Med. 2001;135:248-57.

17. Huong DLT, Amoura Z, Duhaut P. Risk of ovarian failure and fertility after intravenous cyclophosphamide. A study in 84 patients. J Rheumatol. 2002;29:2571-6.

18. Mok CC, Ho CTK, Chan KW, Lau CS, Wong RWS. Outcome and prognostic indicators of diffuse proliferative lupus glomerulonephritis treated with sequential oral cyclophosphamide and azathioprine. Arthritis Rheum. 2002;46:1003-13.

19. Ioannidis JPA, Katsifis GE, Tzioufas AG, Moutsopoulos HM. Predictors of sustained amenorrhea from pulsed intravenous cyclophosphamide in premenopausal women with systemic lupus erythematosus. J Rheumatol. 2002;29:2129-35.

20. Mok CC, Lau CS, Wong RWS. Risk factors for ovarian failure in patients with systemic lupus 
erythematosus receiving cyclophosphamide therapy. Arthritis Rheum. 1998;41:831-7.

21. Sklar CA, Kim TH, Ramsay NK. Testicular function following bone marrow transplantation performed during or after puberty. Cancer. 1984;53:1498-501.

22. Sklar CA, Kim TH, Williamson JF, Ramsay NK. Ovarian function after successful bone marrow transplantation in postmenarcheal females. Med Pediatr Oncol. 1983;11:361-4.

23. Sorror ML, Storer BE, Maloney DG, Sandmaier BM, Martin PJ, Storb R. Outcomes after allogeneic hematopoietic cell transplantation with nonmyeloablative or myeloablative conditioning regimens for treatment of lymphoma and chronic lymphocytic leukemia. Blood. 2008;111:446-52.

24. Alyea EP, Kim HT, Ho V. Impact of conditioning regimen intensity on outcome of allogeneic hematopoietic cell transplantation for advanced acute myelogenous leukemia and myelodysplastic syndrome. Biol Blood Marrow Transplant. 2006;12:1047-55.

25. Rodriguez R, Nademanee A, Ruel N. Comparison of reduced-intensity and conventional myeloablative regimens for allogeneic transplantation in nonHodgkin's lymphoma. Biol Blood Marrow Transplant. 2006;12:1326-34.

26. Matsumoto M, Shinohara O, Ishiguro H, Shimizu T, Hattori K, Ichikawa M, et al. Ovarian function after bone marrow transplantation performed before menarche. Arch Dis Child. 1999;80:452-4.

27. Sanders JE, Hawley J, Levy W. Pregnancies following high-dose cyclophosphamide with or without high-dose busulfan or total-body irradiation and bone marrow transplantation. Blood. 1996;87:3045-52.

28. Wang WS, Tzeng CH, Hsieh RK, Chiou TJ, Liu JH, Yen CC, et al. Successful pregnancy following very high-dose total body irradiation (1575 cGy) and bone marrow transplantation in a woman with acute myeloid leukemia. Bone Marrow Transplant. 1998;21(4):415-7.

Cite this article as: Tan EC, Rajesh H. Spontaneous pregnancy after prepubertal haematopoietic cell transplantation. Int J Reprod Contracept Obstet Gynecol 2018;7:1217-20. 